\title{
Covid-19 Pandemic and its Potential Impact on Sexual and Reproductive Health Indicators in Nigeria
}

\author{
Adeyemo JO, Fagbola MA, Akande AA, OlaOlorun FM, Sekoni 00 and Adebayo AM* \\ Department of Community Medicine, University College Hospital, Nigeria
}

Submission: August 17, 2020; Published: August 24, 2020

*Corresponding author: Adebayo AM, Department of Community Medicine, University College Hospital, Nigeria

\section{Abstarct}

The novel Corona virus disease (COVID-19) pandemic has brought to the fore the true realities and status of health systems globally revealing the gaps and cracks even in seemingly perfect health systems. Although its impact cuts across all sectors affecting life and living as we know it, its impact on health systems globally cannot be fully quantified. Mounting up adequate response to the pandemic has led to diversion of resources and focus from other health necessities, the effect of this may not be noticeable immediately but it has the potential to negatively impact the health of populations and bring a loss in the gains made in global health over the past few decades especially in developing countries. Nigeria, a resource constrained country with a population of about 200million people is not spared, increasing number of new cases are being recorded daily. The fragile and weak health system in the country is also riddled with a lot of sub-optimal health indicators including reproductive health. The reproductive health indices of a population has far and wide reaching impact on the health status of the population however, reproductive health indicators are usually among the worst hit during health emergencies or disasters as seen in the Ebola pandemic in sub-Sahara Africa.

This paper discusses the potential effect of COVID-19 on reproductive health indicators in Nigeria, it is important to anticipate and look out for these effects in order to plan for and ensure early detection and necessary intervention to mitigate such.

Keywords: COVID-19 pandemic; Potential impact; Reproductive health indicators; Nigeria

\section{Perspectives}

Corona virus disease (COVID-19) is the greatest threat to humanity and life as we know it since the turn of the century. The novel corona virus disease detected in 2019 in Wuhan city, Hubei province of China following an outbreak investigation into an upper/lower respiratory airway disease [1]. COVID-19 is suggested to have emanated from an animal source, particularly the large thriving wet animal market in Wuhan. However human to human spread via droplet transmission, and contact with infected surfaces and fomites has since been established. Since first reported in December 2019 till date, there have been over 4 million confirmed cases worldwide with over 300,000 deaths and there seems to be no end yet in sight as new infections continue to increase in numbers each day [2]. COVID-19 was declared a global pandemic by the World Health Organization on $11^{\text {th }}$ March 2020 [3].

The COVID-19 outbreak continues to evolve in the WHO African Region since the first case was reported on 25 February
2020 in Algeria. Since then, all Member States have reported COVID-19. The highest case load has been observed in the West African region, $43 \%$ of total confirmed cases [4]. Nigeria recorded its first case of COVID-19 on $27^{\text {th }}$ February, 2020, an Italian expatriate worker who has since recovered from the illness. However, even though testing facilities are inadequate and contact tracing sub-optimal due to several logistic challenges, over 15,000 cases have been recorded in the country as at $12^{\text {th }}$ June 2020 with increasing number of new cases each day [5]. Infection of health workers is also increasing with Nigeria being the most affected in Africa with 401 health workers infected as at $12^{\text {th }}$ May 2020 rising to 812 by $3^{\text {rd }}$ June 2020 , thereby worsening the strain on the weak health care system $[4,6]$.

Although said to be a largely mild disease with better rates of recovery among the young and healthy with no premorbid disease condition, the ease of spread and the uncertainty around the disease and its history, treatment modalities and full spectrum 
continues to fuel fears globally. Apart from its direct effect on health, numerous other effects spiral from the pandemic. Notable is its immense effect on global economy which is largely from the consequences of measures to reduce spread and mitigate the effect of the disease such as travel bans/restrictions, restriction of movement, lockdown and closure of businesses including manufacturing plants. The world has been said to be having a global economic recession. Also, the broad effect of the global pandemic on health is becoming increasingly evident with the collapse of health systems, shortage of healthcare workers and other essential manpower, scarcity of essential health commodities including personal protective equipment (PPE), diversion of resources from non-COVID cases, interruption and cessation of other health services like family planning and immunization services leading to increased morbidity and mortality from non-COVID causes and leaving a negative impact on health indicators. Health indicators are useful in describing and monitoring a population's health status, they are summary measures that capture relevant information on different attributes and dimensions of health status and performance of a health system. The fragile and weak health system in the country is also riddled with a lot of sub-optimal health indicators including reproductive health. Notably, mounting up adequate response to the pandemic has led to diversion of resources and focus from other health necessities, particularly for the vulnerables comprising children, and reproductive age women, The effects of this may not be noticeable immediately but it has the potential to negatively impact the health of populations and bring a loss in the gains made in global health over the past few decades especially in developing countries.

The reproductive health indices of a population has far and wide reaching impact on the health status of the population however, reproductive health indicators are usually among the worst hit during health emergencies or disasters as seen in the Ebola pandemic in sub-Sahara Africa. This paper discusses the potential effect of COVID-19 on reproductive health indicators in Nigeria. It is important to anticipate and look out for these effects in order to plan for and ensure early detection and necessary intervention to mitigate such.

Reproductive health indicators are largely population-based indicators that provide an overview of the reproductive health situation at the global and national level. There are numerous reproductive health indicators, however WHO's set of 17 indicators as seen later in this paper covers the main reproductive health areas and represents the consensus among international agencies of the key indicators for international and cross-country comparison [6].

Nigeria, a resource constrained country, is generally classified as a low-medium income country, with a population of about 200 million and almost half (40\%) of her population currently living below poverty line. Nigeria's fragile health system suffers largely from health inequalities, both between and within her regions [7]. This stems largely from deep seated corruption at all levels and poor political will in matters pertaining to the health system, evidenced by persistent poor budgetary allocation to health. Some core drivers of Nigeria's poor health indicators include the following: the increasing rate of poverty, limited National Health Insurance Scheme (NHIS) coverage and high rate of out-of-pocket health care financing, declining proportion of functional primary health care, and increasing rate of vertical health intervention [8] Reproductive health indicators in the country are below par and progress has been slow despite numerous interventions, hence the fear of the possible effect of COVID-19 on reproductive health indicators in the country which may worsen the health status and set the country back in the few areas with seeming progress. If adequate measures are not painstakingly taken, it would affect the nation's capacity to meet up with the sustainable development goals, especially goals 3 and 5 .

According to the Nigeria DHS 2018 data, contraceptive prevalence rate was as low as $13 \%$ in 2003 rose to $15 \%$ in 2008 and remained at $15 \%$ in 2013 . However in 2018 the contraceptive prevalence rate was $17 \%$ showing a minimal increase over the years. With a target of moving contraceptive prevalence rate to $27 \%$ by 2020 the pandemic will worsen this index and probably set the country back from the minimal achievements recorded so far $[9,10]$. Response measures against COVID-19 have brought major disruptions against contraceptive supply chains. Principal manufacturers of contraceptives in Asia have had to operate at reduced capacity or stop production. For example, the world's largest condom producer - Malaysia's Karex Bhd- which make a fifth of the world's condoms was shut for one week in March and only reopened at 50\% capacity. This will create a looming scarcity of contraceptive products with anticipated effects on the unmet need for family planning, total fertility rate, contraceptive prevalence rate and the number of clients seeking abortion services.

Maternal and infant mortality rates are social indicators used to measure the development of a country. In the pre COVID-19 era, maternal mortality accounted for 59,000 deaths of women every year in Nigeria and the maternal mortality rate was 3,200 per 100,000 live births which makes Nigeria $2^{\text {nd }}$ (second only to India) in the global maternal incident rate and the worst in Africa [11]. Traditionally, causes of maternal mortality have been explained by the three stages of delay, the first being the delay in making the decision to seek healthcare, the second being the delay in getting to the health care facility after a decision to seek care has been made, and the third delay is the delay in receiving care on arrival at the health care facility [12]. Maternal mortality rate is expected to increase because of the effect of COVID-19 at all 3 stages of the delay. Fear, poverty and stigmatization could prevent prompt decision making while restrictions in movement and inability to afford transport costs could delay arrival at the facility. Furthermore, fear of infection on the part of healthcare workers, overwhelming of the system and reduced manpower and other resources could lead to a delay in receiving care on arrival at the 
health care facility.

A reduction in antenatal care coverage and percentage of births attended by skilled health personnel is also anticipated as women may prefer to give birth at home and with traditional birth attendants. This in turn may cascade into increased perinatal mortality rate as early neonatal interventions to prevent neonatal deaths are not available at home, mission houses and traditional birth centres. Currently, availability of basic and comprehensive essential obstetric care is on the decline during this pandemic due to diversion of resources, including manpower, to manage COVID-19 cases. To compound the problems, health workers themselves may become infected, further depleting the available scarce manpower. However, an increase in availability of essential obstetric care is anticipated post COVID-19. This is expected because of the scale up and renovations of facilities during the pandemic. Perinatal mortality rates, low birthweight prevalence and anemia in women may also increase due to the lack of skilled monitoring during pregnancy and childbirth. Female genital cutting (FGC) may also increase due to the reduced visibility and weakened legal system. The attention of law enforcement agents are diverted to COVID-19 mitigation and courts are currently not sitting to address issues relating to violation of rights of girls like FGC, rape and other forms of abuse.

The effect of COVID-19 on HIV prevalence is worthy of note as currently those living with HIV now risk having their treatment interrupted due to reduced access to HIV services which are either closed or because of disruptions to the supply chain of antiretroviral therapy. The disruption in supply chain may be because services have become overwhelmed due to competing needs to support the COVID-19 response [13]. A critical priority during the COVID-19 pandemic is ensuring continuity of treatment and support for viral suppression among pregnant women living with HIV (PLHIV); reducing the risk of mother to child transmission and helping those who are at risk of HIV acquisition to remain HIV negative [14].

Also during this current epidemic, measures such as social distancing and isolation are being used to mitigate and reduce transmission; however these measures may have negative impact on some families. Family members spend more time in close contact and families cope with additional stress and potential economic or job losses and for women especially those in abusive relationships, these stressors may increase the prevalence of gender based violence, including sexual violence which in turn may lead to unwanted pregnancies, thereby worsening our reproductive health indices. Evidence of increasing intimate partner violence has been documented in China and the USA during this pandemic [15]. Suffice to say that there are anecdotal evidences in Nigeria regarding gender based violence involving adolescent girls and young women. Some of the victims were raped and killed in the process, worsening the death toll in the country $[16,17]$.
Sexual and reproductive health services are central to health, rights, and well-being of women and girls. The diversion of attention and critical resources away from these provisions may result in exacerbated maternal mortality and morbidity, increased rates of adolescent pregnancies, HIV, and sexually transmitted diseases.

School closures lead to many consequences, such as: loss of education and learning; some adolescents dropping out of school permanently leading to increased risk of sexual exploitation and forced early marriage [18]. Reduction of access to sexual and reproductive health information and services for adolescent girls reduces protection from sexually transmitted infections and may increase teenage pregnancies, unwanted births and health risks to adolescent mothers and infants [12]. Women's education has been shown across studies to have an influence on their empowerment and contraceptive uptake with the most educated being more responsive to the use of modern contraceptive methods [19]. Lack of education or increased school dropouts owing to the effects of COVID-19 may in the nearest future add to population explosion from increased births [20-23].

Of note is the economic impact of COVID-19 on women's financial empowerment, a lot of jobs largely done by women are affected by the trade and movement restriction. This increases their vulnerability and worsens their reproductive and other health indices as most of the health care financing is done from out of pocket payments with only limited NHIS coverage. These anticipated effects on reproductive health indicators are listed in Table 1 below.

Borrowing lessons from the Ebola disease outbreak of 2014 -2016 in Liberia, Guinea and Sierra Leone, it is important to anticipate and forecast such effects so that interventions can be put in place to mitigate the impacts. There was a huge surge in maternal mortality rates during and after the Ebola outbreak as women stayed away from medical facilities due to quarantine restrictions or misconceptions about virus transmission and were forced instead into riskier home births. Maternal mortality rates in Sierra Leone soared, back to the grim high points observed in the 1991-2002 civil war. The decrease in utilization of lifesaving health services translated to 3,600 additional maternal, neonatal and stillbirth deaths in the year 2014-15 under the most conservative scenario $[14,15]$.

The graph below shows the declining levels of institutional deliveries and antenatal care visits before, during and after the Ebola outbreak from January, 2013 to February, 2016 from a retrospective observational cohort study on the effect of Ebola virus disease on maternal and child health services in Guinea by Alexandre Delamou et al. [16]. Number of women receiving at least one or at least three antenatal care visits and number giving birth in a health facility, Forest region, Guinea from January, 2013, to February, 2016. 
Interventions must be put in place so that the pandemic does not set Nigeria back from any gain made in reproductive health over the years. Watchful observation and surveillance must be put in place to pick any negative impact in good time so as to nip it in the bud. The UNFPA in its global response plan for COVID-19 highlights 3 strategic priorities viz: Continuity of sexual and reproductive health services and interventions including protection of the health workforce and prevention of the diversion of health workers away from reproductive health services; addressing gender based violence and; ensuring supply of modern contraceptives and other reproductive health commodities ${ }^{17}$ by strengthening national and regional supply chains.

In addition, relevant govenmental ministries, parastatal and agencies should increase awareness, and continuous engagement with the communities and stakeholders to sustain and maintain the progress in reproductive health, particularly at a time like this. Actions must be targeted towards the most vulnerable groups in communities by various cadres of health workers and relevant non-governmental organizations through provision of counselling, psychological support and virtual consultations. Improvement in telemedicine is a much needed approach worth considering going forward. Finally, as much as COVID-19 and its attendant sequelae appears novel, efforts should be put in place by the government and all the stakeholders to consider and mitigate its effect on reproductive health because therein lies the future of humanity.

\section{Appendix}

\section{Reproductive health indicators and their definitions ${ }^{6}$}

a) Total Fertility Rate (TFR)- Total number of children a woman would have by the end of her reproductive period if she experienced the currently prevailing age-specific fertility rates throughout her childbearing life

b) Contraceptive Prevalence Rate (CPR)- Percent of women of reproductive age (15-49) who are using (or whose partner is using) a contraceptive method at a particular point in time

c) Maternal Mortality Ratio (MMR)- Annual number of maternal deaths per 100,000 live births

d) Antenatal Care Coverage- Percent of women attended at least once during pregnancy, by skilled health personnel for reasons relating to pregnancy.

e) Percent of Births Attended by Skilled Health Personnel- Percent of births attended by skilled health personnel

f) Availability of Basic Essential Obstetric Care- Number of facilities with functioning basic essential obstetric care per 500,000 population

g) Availability of Comprehensive Essential Obstetric Care -Number of facilities with functioning comprehensive essential obstetric care per 500,000 population

h) Perinatal Mortality Rate (PMR)- Number of perinatal deaths per 1,000 total births

i) Low Birth Weight Prevalence- Percent of live births that weigh less than 2,500g

j) Positive Syphilis Serology Prevalence in Pregnant Women- Percent of pregnant women (15-24) attending antenatal clinics, whose blood has been screened for syphilis, with positive serology for syphilis

k) Prevalence of Anemia in Women- Percent of women of reproductive age (15-49) screened for hemoglobin levels with levels $110 \mathrm{~g} / \mathrm{l}$ for pregnant women, and $120 \mathrm{~g} / \mathrm{l}$ for non-pregnant women

I) Percent of Obstetric and Gynecological Admissions Owing to Abortion

m) Reported Prevalence of Women with female genital cutting.

n) Prevalence of Infertility in Women- Percent of women of reproductive age (15-49) at risk of pregnancy (not pregnant, sexually active, non-contracepting, and non-lactating) who report trying for a pregnancy for two years or more

o) Reported Incidence of Urethritis in Men Percent of men aged (15-49) interviewed in a community survey reporting episodes of urethritis in the last 12 months

p) HIV Prevalence among Pregnant Women.

q) Knowledge of HIV-related Prevention Practices-Percent of all respondents who correctly identify all three major ways of preventing the sexual transmission of HIV and who reject three major misconceptions about HIV transmission or prevention 


\section{References}

1. Rothan HA, Byrareddy SN (2020) The epidemiology and pathogenesis of coronavirus disease (COVID-19) outbreak. J Autoimmun 109: 102433.

2. World Health Organization (2020) WHO Coronavirus Disease (COVID-19) Dashboard. Covid-19 Dashboard.

3. Biddlecom A, Riley T, Sully E, Ahmed Z (2020) Estimates of the Potential Impact of the COVID-19 Pandemic on Sexual and Reproductive Health In Low- and Middle-Income Countries. Int Perspect Sex Reprod Health 46: 73-76.

4. World Health Organization (2020) COVID-19 WHO african region external situation report 11. Heal Emerg Inf Risk Assess, pp. 1-10.

5. Nigeria Center for Disease Control (2020) Covid-19 Situation Report Situation Report 38. NCDC covid19 Situat reoprt 38. 1(38): 19-21.

6. Tih F (2020) Nigeria: 800 health workers infected with COVID-19. World, Africa, Latest on Coronavirus Outbreak, pp. 1-3.

7. National Bureau of Statistics (NBS) (2020) 2019 Poverty and Inequality in Nigeria: Executive Summary, pp. 1-27.

8. Tilley-Gyado R, Filani O, Morhason-Bello I, Adewole IF (2016) Strengthening the primary care delivery system: A catalytic investment toward achieving universal health coverage in Nigeria. Heal Syst Reform 2(4): 277-284.

9. National Population Commission (NPC) [Nigeria], ICF. (2019) Nigeria Demographic Health Survey 2018. DHS Progr ICF Rockville, Maryland, USA, p. 748.

10. (2020) Total Fertility Rate in Nigeria Decreases Slightly as the Contraceptive Prevalence Rate Increases. JHU - Advance Family Planning.

11. Olonade O, Olawande TI, Alabi OJ, Imhonopi D (2019) Maternal mortality and maternal health care in Nigeria: Implications for socioeconomic development. Open Access Maced J Med Sci 7(5): 849-855.
12. Thaddeus S, Maine D (1994) Too far to walk: Maternal mortality in context. Soc Sci Med 38(8): 1091-1110.

13. World Health Organisation (2020) The cost of inaction: CoVID-19related service disruptions could cause hundreds of thousands of extra deaths from HIV.

14. USAID, PEPFAR, Epic (2020) Strategic Considerations for Mitigating the Impact of COVID-19 on Key- HIV Programs (7200). Pp. 1-16.

15. World Health Organization (2020) WHO Timeline - COVID-19 and violence against women What the health sector/system can do. Sexual and reproductive health pp. 1-3.

16. CNN (2020) Nigeria: State governors resolve to declare state of emergency on rape - CNN.

17. Premium Times (2020) Rape cases increase as 12-year-old is gangraped in Lagos.

18. United Nations Children's Fund (UNICEF) (2020) Technical Note on Covid-19 and Harmful Practices.

19. Olugbenga-Bello AI, Adeyemi A, Adeoye O, Salawu M, Aderinoye A, et al. (2016) Contraceptive prevalence and determinants among women of reproductive age group in Ogbomoso, Oyo State, Nigeria. Open Access J Contracept 7: 33-41.

20. Beech P (2020) COVID-19 could have effects on women's health, says the UN. World Economic Forum.

21. Sochas L, Channon AA, Nam S (2017) Counting indirect crisis-related deaths in the context of a low-resilience health system: The case of maternal and neonatal health during the Ebola epidemic in Sierra Leone. Health Policy Plan 32(Suppl_3): iii32-iii39.

22. Delamou A, Ayadi AME, Sidibe S, Therese D, Bienvenu SC, et al. (2017) Effect of Ebola virus disease on maternal and child health services in Guinea: a retrospective observational cohort study. Lancet Glob Heal 5(4): e448-e457.

23. Coronavirus Disease (COVID-19) (2020) Pandemic UNFPA Global Response Plan.

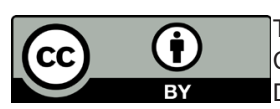

This work is licensed under Creative Commons Attribution 4.0 License DOI: 10.19080/JGWH.2020.19.556016

\section{Your next submission with Juniper Publishers will reach you the below assets}

- Quality Editorial service

- Swift Peer Review

- Reprints availability

- E-prints Service

- Manuscript Podcast for convenient understanding

- Global attainment for your research

- Manuscript accessibility in different formats

( Pdf, E-pub, Full Tsext, Audio)

- Unceasing customer service

Track the below URL for one-step submission https://juniperpublishers.com/online-submission.php 